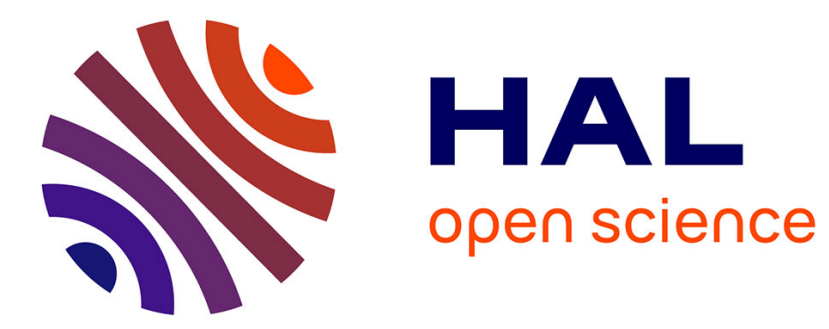

\title{
COMPOSITION OSCILLATIONS IN HARD MATERIAL LAYERS DEPOSITED FROM THE VAPOUR PHASE
}

K. Bartsch, A. Leonhardt, E. Wolf

\section{- To cite this version:}

K. Bartsch, A. Leonhardt, E. Wolf. COMPOSITION OSCILLATIONS IN HARD MATERIAL LAYERS DEPOSITED FROM THE VAPOUR PHASE. Journal de Physique IV Proceedings, 1991, 02 (C2), pp.C2-563-C2-570. 10.1051/jp4:1991267 . jpa-00249857

\section{HAL Id: jpa-00249857 https://hal.science/jpa-00249857}

Submitted on 1 Jan 1991

HAL is a multi-disciplinary open access archive for the deposit and dissemination of scientific research documents, whether they are published or not. The documents may come from teaching and research institutions in France or abroad, or from public or private research centers.
L'archive ouverte pluridisciplinaire HAL, est destinée au dépôt et à la diffusion de documents scientifiques de niveau recherche, publiés ou non, émanant des établissements d'enseignement et de recherche français ou étrangers, des laboratoires publics ou privés. 
Colloque C2, suppl. au Journal de Physique II, Vol. 1, septembre 1991

\title{
COMPOSITION OSCILLATIONS IN HARD MATERIAL LAYERS DEPOSITED FROM THE VAPOUR PHASE
}

\author{
K. BARTSCH, A. LEONHARDT and E. WOLF \\ Central Institute of Solid state physics and Materials \\ Research, Helmholtzstr. 20, D-0-8027 Dresden, Germany
}

\begin{abstract}
For the deposition of hard layers on hard metals from the gas phase in the systems $T i-C-B, T i-N-B, T i-V-C-O$, $\mathrm{Ti}-\mathrm{Zr}-\mathrm{C}$, Ti-C-N, Ti-C, B-C and $\mathrm{Si}-\mathrm{C}$ at selected deposition conditions the existence of oscillations was established, which result in a lamellar structure of the layers. As shown by Auger-Spectroscopic analyses the composition of the lamellas changes alternately. Reasons for the lamellar deposition are discussed and a qualitative macroscopic model is presented.
\end{abstract}

\section{Introduction}

The existence of oscillating reactions in homogeneous and heterogeneous systems has been known for a long time [1-5]. In spite of constant reaction conditions for the deposition of solids from the gas phase such oscillations can cause periodical changes of composition and structure, respectively, which appear as more or less perfectly formed lamellar structure of the material deposited. Thus FITZER [2] noticed for instance for the deposition of carbides of silicon, boron and titanium together with free carbon layers, which were constructed alternatively from lamellas with changing carbon content. Laminar depositions were also obtained by GULDEN [4] for the coating of spherical particles with Sic in a fluidized bed.

Similar effects, which were noticed for the coating of hard metals with hard coatings, have been investigated more in detail in this study. The essential experimental results and the attempt at a qualitative macroscopic explanation are reported now.

\section{Experimental}

The layer deposition was performed by chemical gas phase deposition (CVD) at normal pressure in the temperature range of $1250-1400 \mathrm{~K}$. For this purpose both hot wall and cold wall reactors were used. Moreover layers were also prepared by plasma-activated deposition (PACVD) ( $r f-$ and dc-discharge) at total pressures between $0,1-1,0$ $\mathrm{KPa}$ and deposition temperatures below $1173 \mathrm{~K}$. As starting substances the corresponding metal chlorides, hydrogen, nitrogen and benzene or n-heptane, respectively, were used. For the deposition of vanadium containing layers Vocl $_{3}$ was used as vanadium carrier as well as $\mathrm{ZrI}_{4}$ for zirconium containing layers. Commercial WC-Co-hard metal cutting plates were used as substrates. In the case of 
deposition of boron containing layers intermediate layers (e. $g$. TiN, TiC) as diffusion barriers were deposited to avoid interactions between the substrate and the boron containing layer. For the characterization of the layers at first metallographic techniques were used. Commonly, the detection of lamellar structure is possible by optical microscopy after wet chemical etching $\left(\mathrm{HF} / \mathrm{HNO}_{3} / \mathrm{H}_{2} \mathrm{O}\right.$ ) at straight or inclined sections. With selected examples the layer composition was investigated in detail by Auger-spectroscopy, EDXand WDX-measurements as well as by X-ray diffraction.

\section{Results}

In Table 1 the investigated systems are shown, in which layers with oscillating structure could be deposited. Furthermore, in this table also data of layer composition and the used deposition techniques are given.

Table 1 Investigated systems

(CWR-cold wall reactor, HWR-hot wall reactor)

\begin{tabular}{|c|c|c|c|}
\hline system & deposited phases & method & substrate temperature \\
\hline $\mathrm{Ti}-\mathrm{C}-\mathrm{B}$ & $\begin{array}{l}\text { TiC }_{X}+\mathrm{TiB}_{2} \\
\text { (partially poor } \\
\text { crystalinity) }\end{array}$ & CVD, CWR & $1300 \mathrm{~K}$ \\
\hline $\mathrm{Ti}-\mathrm{N}-\mathrm{B}$ & $\operatorname{TiN}_{\mathbf{x}}+\mathrm{TiB}_{2}$ & CVD, CWR & $1300 \mathrm{~K}$ \\
\hline$B-C$ & $\left.{ }_{(x}^{\mathrm{B}_{x}} \mathrm{C}+{ }_{7}\right)^{\mathrm{B}_{25}} \mathrm{C}$ & CVD, CWR & $1300 \mathrm{~K}$ \\
\hline $\mathrm{Ti}-\mathrm{C}-\mathrm{N}$ & $\mathrm{Ti}_{\mathrm{x}^{\mathrm{N}}} \mathrm{C}_{1-\mathrm{y}}$ & CVD, CWR & $1300 \mathrm{~K}$ \\
\hline $\mathrm{Ti}-\mathrm{C}$ & $\operatorname{TiC}_{\mathbf{x}}$ & $C V D, C W R$ & $1300 \mathrm{~K}$ \\
\hline $\mathrm{Ti}-\mathrm{V}-\mathrm{C}-\mathrm{O}$ & $(\mathrm{Ti}, \mathrm{v}) \mathrm{C}_{1-\mathrm{x}} \mathrm{O}_{\mathrm{x}}$ & CVD, HWR & $1323 \mathrm{~K}$ \\
\hline $\mathrm{Ti}-\mathrm{Zr}-\mathrm{C}$ & $(\mathrm{Ti}, \mathrm{Zr}) \mathrm{C}_{\mathrm{x}}$ & CVD, HWR & $1323 \mathrm{~K}$ \\
\hline Si-C & $\begin{array}{l}\text { si (amorphous) } \\
+\operatorname{sic} \text { (amorphous) }\end{array}$ & $\begin{array}{l}\text { PACVD, CWR } \\
\text { rf-discharge }\end{array}$ & $1043-1173 \mathrm{~K}$ \\
\hline Tic & $\operatorname{TiC}_{x}$ & $\begin{array}{l}\text { PACVD, CWR } \\
\text { (dc-, rf- } \\
\text { discharge) }\end{array}$ & $<950 \mathrm{~K}$ \\
\hline
\end{tabular}

From Table 1 follows that a lamellar structure can be formed in the layer both at single phase and at multiphase deposition. In Figs. 1 and 2 the micrographs of two typical examples are shown. The lamella thickness is between 0,1 and 1 um. In the case of the single phase ( $\mathrm{Ti}, \mathrm{V}) \mathrm{C}_{1-\mathrm{x}} \mathrm{O}_{\mathrm{x}}$-layers lattice constant measurements, at which a reflex splitting was established (2 lattice constants determinable) were indicative of existent differences in composition in the lamellas.

For the systems $\mathrm{Ti}-\mathrm{C}-\mathrm{B}[9], \mathrm{Ti}-\mathrm{V}-\mathrm{C}-\mathrm{O}$ and $\mathrm{Si}-\mathrm{C}$ it could be established by Auger-spectroscopic measurements at $6^{\circ}$-inclined sections that the composition of the lamellas oscillates.

In Figs. 3 and 4 examples for such oscillations in a ( $\mathrm{Ti}, \mathrm{V}) \mathrm{C}_{1-\mathrm{x}_{\mathrm{X}}} \mathrm{O}^{-}$ and $\mathrm{TiC}_{\mathrm{x}} / \mathrm{TiB}_{2}$-layer, respectively, are shown. At the single phase $(\mathrm{T} i, \mathrm{~V}) \mathrm{C}_{1-\mathrm{x}^{\circ}} \mathrm{x}^{-1 a y e r}$ the $\mathrm{Ti} / \mathrm{V}-\mathrm{ratio}$ alternates from lamella to 
lamella, at the $\mathrm{TiC}_{\mathrm{X}} / \mathrm{TiB}_{2}$-layer the $\mathrm{C} / \mathrm{B}-$ ratio as well as at the Si+Sic-layer the C/Si-ratio alternates.

Analogies can be expected for the systems Ti-N-B, Ti-Zr-C, Ti-C-N and $B-C$. In the case of $T$ ic -deposition by PACVD the Ti/C-ratio should oscillate, because these layers were strongly understoichiometric $(x<1)$ according to element analysis. But oscillations could not be detected by Auger-spectrometric analyses [8].

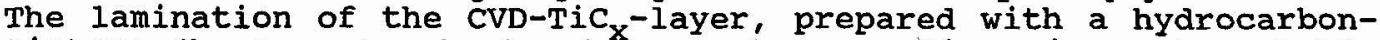
mixture (benzene $+n$-heptane) as carbon supplier, is most probably mainly an effect in structure. It is known, that for the Tic deposition using benzene and n-heptane, respectively, different growth induced textures will be formed (benzene: <111>, n-heptane: $<100>$ ) $[6,7]$.

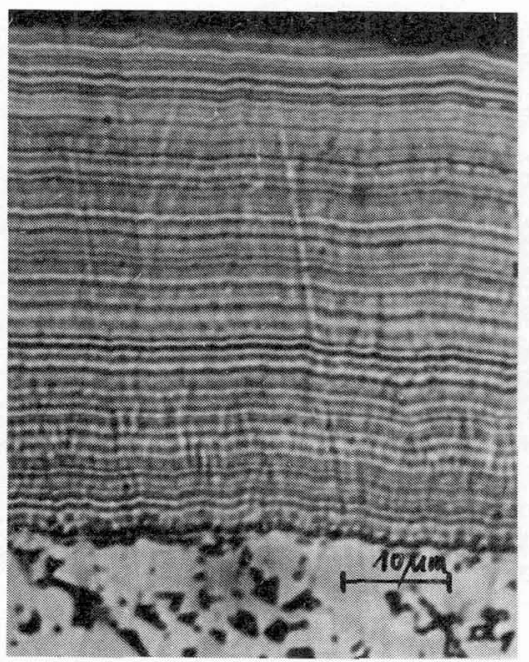

Fig. 1 (Ti,V) $C_{1-x} \mathrm{O}_{x}-$ layer

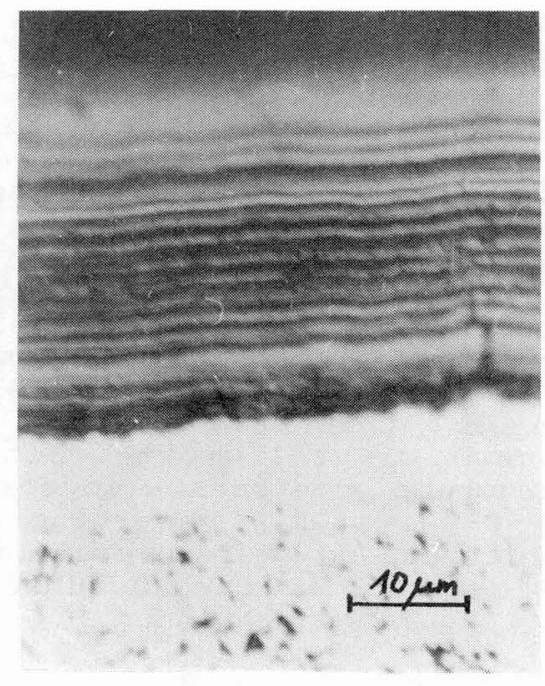

Fig. $2 \mathrm{TiC}_{\mathrm{x}}+\mathrm{TiB}_{2}$-layer

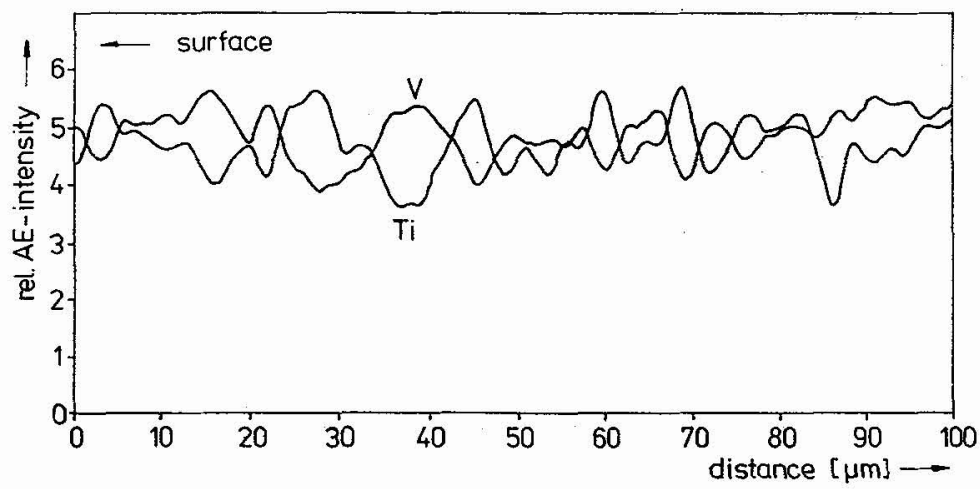

Fig. 3 Auger-line scan over a $(\mathrm{Ti}, \mathrm{V}) \mathrm{C}_{1-\mathrm{x}} \mathrm{O}^{- \text {-layer }}$ 


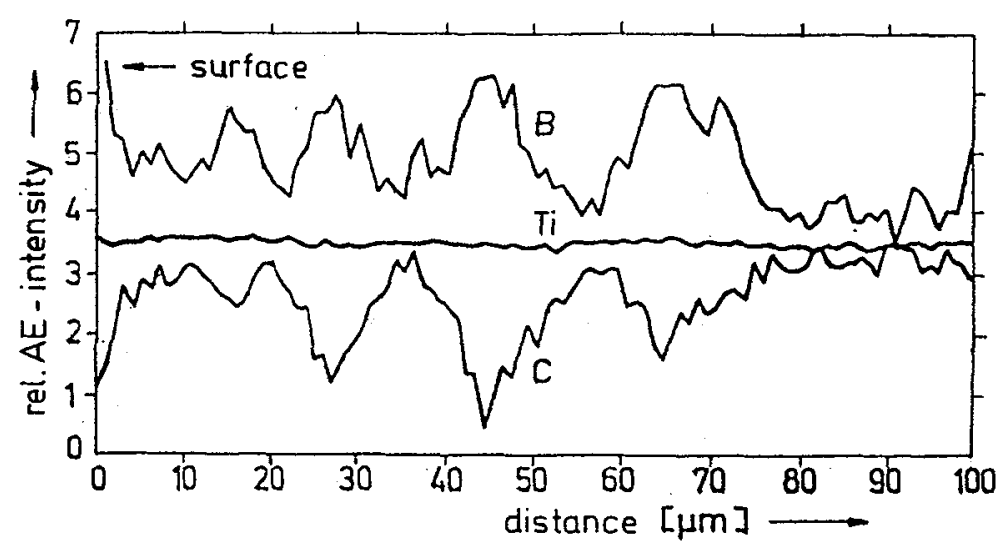

Fig. 4 Auger-line scan over a $\mathrm{TiC}_{\mathrm{x}}+\mathrm{TiB}_{2}$-layer

The element composition of the heterogeneous depositions determined by Auger-spectrometric investigations shows that the lamellas must be regarded as multiphase systems $\left(\mathrm{TiC}_{\mathrm{X}}+\mathrm{TiB}_{2}\right.$ and $\mathrm{Si}+\mathrm{SiC}$, respectively) with phase ratios changing from lamella to lamella.

The finestructure of multiphase lamellas could not be observed by optical microscopy, because of an unsufficient resolution. One can proceed on the assumption that lamellar layers as a rule have a lower grain size than hard material monolayers, which in general show a columnar crystal growth. But in single phase layers with lamellar structure sometimes also epitaxial growth was found (e.g. in the Ti-V-C-O-system), resulting in the formation of columnar crystals, which extend over several lamellas.

Some specific facts, which can substantiate the interpretation of the results, should be mentioned:

1. The first deposited lamella always has that phase composition which is connected with the higher deposition rate in comparison to the composition of the adjacent lamella.

2. The occurrence of lamellar structures is dependent on geometry and flow conditions in the hot wall reactor. High flow rates can lower the lamella thickness and differences in concentration between the lamellas, respectively (e.g. at $\left.\mathrm{TiC}_{\mathrm{x}}+\mathrm{TiB}_{2}\right)$.

3. High deposition temperatures ( $\mathrm{T}=1473 \mathrm{~K}, \mathrm{Ti}-\mathrm{C}-\mathrm{B}-\mathrm{system}$ ) prevent the formation of lamellar structure.

4. With lowering the deposition temperature the thickness of the lamellas decreases.

These facts indicate the phenomenon of oscillating deposition is based on kinetics. The only fact that at a given composition of the gas phase in the initial state and constant deposition temperature, different final states (different compositions of the lamellas) will be obtained, which cannot be explained by a thermodynamically controlled deposition process. The deposition rates in the Ti-C-Bsystem (Fig. 5), determined experimentally for dependence on flow rate, also point to the existence of kinetically controlled processes. At low B/Ti-ratios in the gas phase no effect of the flow rate on the deposition rate was established. 


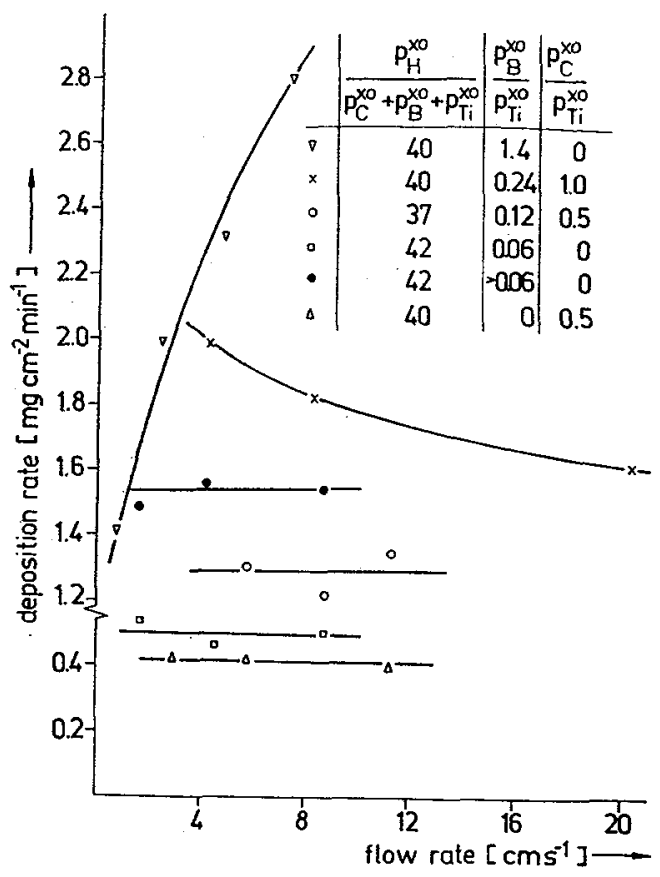

Fig. 5 Deposition rates for the system Ti-C-B, CWR, $1300 \mathrm{~K}$

\section{Model of oscillating deposition}

For explanation of the lamellar deposition phenomenon a model has been developed by FITZER [2], the main assumptions of which are the existence of a back mixing zone at the solid-gaseous interface and the autocatalytic acceleration of partial reactions in this back mixing zone. Indication of autocatalytic effects in hard material deposition was not found. We are of the opinion that for the material variety of the systems, in which lamellar growth was observed, the autocatalytic concept should probably not be suitable in general. In the following we present a simple model, which explains qualitatively the formation of oscillating concentration fluctuations during deposition without the assumption of autocatalytic effects. The only necessary precondition is the assumption of kinetic inhibitions different in strength at the deposition of those phases or components, which are participants at the oscillations.

Further explanations are made by means of the schematic in Fig. 6 , in which the progress of the deposition rate $(v)$ of component $A$ and $B$ is shown as dependent on time.

For the deposition of the component B lower kinetic constraints as well as a deposition rate higher than that for component $A$ are assumed. From the first assumption follows, that the deposition of $A$ and $B$ should reach a steady state after different times $t_{1}$ and $t_{2}$ (dotted line in fig. 6). At the steady state for the ratio B:A in the solid deposited the following is valid:

$$
\frac{n_{B}^{s t}, s}{n_{A}^{s t}, s}=\frac{n_{B}^{\circ}, g-n_{B}^{s t}}{n_{A}^{\circ}, g-n_{A}^{s t}, g}=\frac{v_{B}^{s t}}{v_{A}^{s t}}
$$

(n - atomic concentration, s - solid, g - gaseous, $\mathrm{n}^{\circ}$ - atomic concentration at initial state, st - steady state) 
Because the deposition rate of $B$ increases more rapidly than that of $A$, at time $t_{1}$ the gas phase composition as well as the solid composition differ from steady state.

Assuming that $n_{B, g} \approx n_{B, g}^{s t}$, at time $t_{1}$ is:

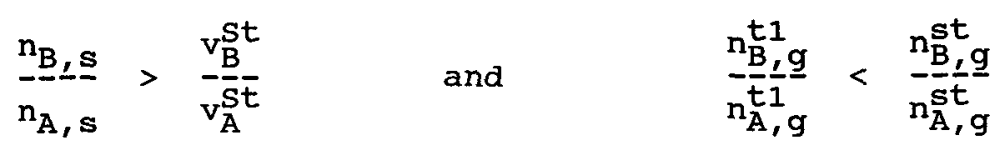

The departure from steady state at the solid-gaseous interface, built up till $t_{1}$, operates as an increase of the initial ratio $n_{\AA}^{\circ}, g / n_{B}^{\circ}, g$. Hence $t i l l t_{2} v_{A}$ rises to $v_{A}>v_{A}^{S t}$ and $v_{B}$ decreases (full lines in fig. 6), because the total deposition rate must be constant in the steady state. At $t_{2}$ it is:

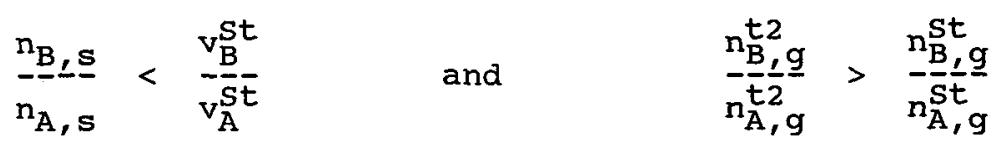

Thus till t2 a gas phase composition has built up, which operates as a decrease of the initial ratio $n_{A, g}^{\circ} / n_{B}^{\circ}, g^{*}$

Consequently, $v_{B}$ increases again to $v_{B}>v_{B}^{S t}$ till $t_{3}$, because by reason of its lower time dependence $v$ cannot follow. In the further progress of deposition $v_{B}$ and $v_{A}$ oscillate about $v_{B}^{S t}$ and $v_{A}^{S t}$, respectively, with a phase shifting of $t_{n}-t_{n-1}$.

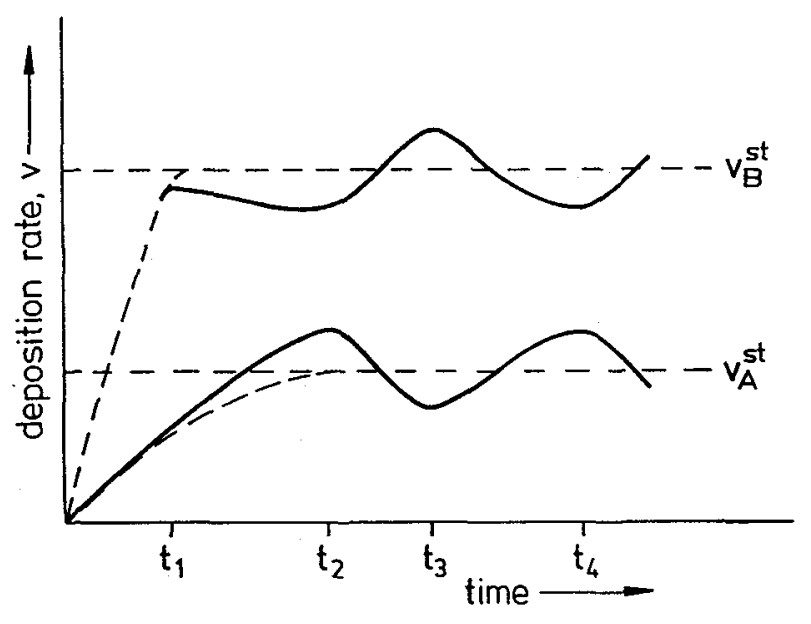

Fig. 6 The time dependence of deposition rate (schematically) 


\section{Discussion of results}

The deviation of the deposited materials composition from the composition in steady state $\left(v_{B}^{S E} / v_{A}^{S t}\right)$ runs through an extreme value at $t_{n}$. Examples of such changes in composition in the deposited layers, established by Auger-spectroscopy were shown in Figs. 3 and 4. According to the oscillation model proposed an asymmetry of the concentration profile in the lamella can be expected, because $t_{n}-t_{n-1} \neq t_{n+1}-t_{2}(n \geq 2)$. In the Auger-spectra this effect sometimes appears, but it is not detectable definitely. The formation of a lamellar structure assumes for times of nearly $t_{n+1}-t_{n}$ the maintenance of an instationary state at the gaseous-solid interface. Estimations of these times from the number of lamellas and the deposition time led to values of up to about $20 \mathrm{~s}$. The unstable state is influenced by the flow conditions at the substrate and should be overcome with increasing gas flow rate. A decay of the concentration oscillations with the deposition time or a decrease of the changes in concentration or their total inhibition could be a consequence. The latter fact was established experimentally in the systems $T i-C-B$ and $T i-2 r-C$. The decay of the oscillations was observed in the Si-c-system.

The discussed concept also enables the explanation of the observed dependence of the lamella thickness on temperature (Ti-V-C-O-, si-c-system). With decreasing temperature the deposition rates diminish. Provided that the temporal shift until reaching a stationary state of the deposition of $B$ and. $A$ is nearly temperature independent, the lamelia thickness must decrease.

The detection of oscillations for the deposition of $\mathrm{TiC}_{\mathrm{X}}$ under CVDconditions and simultaneous use of two hydrocarbons (n-heptane and benzene) can be regarded as indirect confirmation of the main assumption of the model presented above, because benzene and $n-$ heptane show a very different deposition behaviour $[6,7]$.

\section{Conclusions}

The formation of lamellar structures for the deposition of solids from gas phase is a kinetic effect. A qualitative macroscopic explanation of this phenomenon without specific assumptions is possible under the precondition that at least two partial reactions are differently kinetically inhibited. With the model presented the experimental findings are explainable.

Fundamentally the occurrence of lamellar structures can be expected for deposition, if there are non-equivalent conditions (PACVD) or for the deposition under conditions, which counteract an equilibrium state (low deposition temperature, cold wall reactors).

Besides concentration oscillations also aternating changes in structure can cause a lamellar structure. 


\section{References}

[1] Field R. J., Burger H., (Eds.), Oscillations and Travelling Waves in Chemical systems, Wiley, New York 1984

[2] Fitzer E., Chemie-Ing.-Techn. 41, 5+6 (1969) 331

[3] Fitzer E., Hegen D., Angew. Chem. 91 (1979) 316

[4] Gulden T. D., J. American Ceramic Soc. 51, 8 (1968) 424

[5] Ertl G., Phys. Bl. 46 (1990) 339

[6] Leonhardt A., Wolf E., Schönherr M., seidler M., Bartsch K., Selbmann D., Neue Hütte 31,11 (1986) 423

[7] Leonhardt A., Schläfer D., Seidler M., Selbmann D., Schönherr M., J. Less-Common Metals 17 (1982) 63

[8] Täschner Ch., Leonhardt A., Schönherr M., Wolf E., Henke J., paper held on Second Internat. Conf. on Plasma Surface Engineering, sept. 10-14, 1990, Garmisch-Partenkirchen, FRG, to be published in J. Mater. Sc.

[9] Bartsch K., Leonhardt A., Wolf E., Schönherr M., to be published in J. Mater. Sc. 